\title{
DEVELOPING LITERATURE PROGRAM FOR CHILDREN
}

\author{
Yasmin Farani \\ University of Merdeka Malang \\ yasmin.farani@unmer.ac.id
}

\begin{abstract}
Education today has given great attention on children and their phsycological state. However, it is hardly given attention that books as the material for teaching in child education play as important role as those for adults. This is more urgent especially when televisions or visualized media have much influence on the children. This certainly leads to the consequence that children today might not manage to develop what the cognitivists call cognitive controlsystem (see Swaan, 1993, Alberson(1981), Van Dijk and Kintsch(1983). This paper, in general aims at demonstrating that literature program for children today can give more humanistic picture to education or in other words it will treat children education not as mechanistic as before.
\end{abstract}

Keywords: children, education, literature.

Today, there is an abundance of books for children that never been published before in Indonesia. Those books vary from comic to storybooks; some are translated while others are written by Indonesian writters. At a glance, it seems that the Japanese comics are the most popular ones, one fact that has put many educationists in doubtful position. It might be easily agreed that the growing interest for reading among children can be promising, but there soon appears questions concerning the pedagogic advantage of such books for the children. Meanwhile, many cognitivists have done researches on the usefulness of literary reading (Gibbs, et. Al, 1991; Striedter, 1989). From the published books for children, the questions appears, how shall teachers, librarians, and parents select that which is literature? In order to answer this question, it is necessary to, firstly, define what literature is and what literature is appropriate for children. 
Literature is simply the imaginative shapping of life and thought into the forms and structures of language (Huck, 1976). The province of literature is the human condition; life with all its feeling, thoughts and insights. The experience of literature is always two dimensional, for it involves both the book and reader. Some critics suggest that Carrol's Alice in Wonderland the greatest book ever been written for children. However, if the child has no background in fantasy, he will not be able to interact with the book and thus fails experiencing literature. This is simply because he cannot comprehend the complexity of the plot, nor tolerate the logic of its logic, for example the 'nonsense' of the poem Jabberwocky in the book. One many then ask how a child could successfully experience literature? Huck (1976) suggested the use of words and pictures which are presented in such a way to enable the readers to be aware of an order, a unity, a balance or a new frame of reference. It will cause readers to perceive charcaters, conflicts, elements in a setting, and universal problems of makind and also experience the humor, beauty, wonder or the despair of sorrow.

\section{WHAT IS CHILDREN'S LITERATURE?}

It can be said that a child's book is a book read by children, while an adult book is a book occupying the attention of an adult. Before the nineteenth century only a few books were written for the specific readership of children in the west. Children read books written for adults, taking from them what they could understand. In Indonesia, the case is worse for hardly any attention is given on the publication of children book. 
Children today are more sophisticated and know knowledgeable then any other generation of their age has been. They spend more time viewing television than they spend in school. The evening news has shown them actual views of Iraq war and many others. While the modern child is separated from first-hand knowledge of birth, death, and seniliy, the mass media has brought him the vicarious and daily experience of crime, poverty, war, sex, divorce, and murder.

Such exposure has forced many educationists to reconsider what seems appropriate for children's literature. Children's books are reflecting the problems of life prom the children's perspective. However, it should be noticed that the content of the literature is limited by the experience and understanding of children. Certain emotional and phsycological responses seem outside the realm of childhood, for example the feeling of nostalgia is an adult emotional that is foreign to children. They seldom look back on their childhood, but always forward. Children see beauty where there is uglines; they are hopeful when adults have given up. O Henry's Ransom of the Red Chief is a good example of literature for children with its light, humorous, and sensitive tone because it treats serious crime of kidnapping as an entertaining one.

The uniqueness of children's literature lies in the audience that it addresses readers with unique perspective. Most of authors of children's books are sircumscribed only by the experience of childhood which are vast and complex. The child is always curious about life and adults activities, the lives in the midst of tensions, of balances of love, and life within the family and the neighborhood. 


\section{CHOOSING BOOK FOR CHILDREN}

It has been well assumed that the first thing a child usually responds to a book is the emotional aspect. In choosing the appropriate books for children, one must firstly know the structures and forms of literature and at the same time know the structure of children's thought, language acquisition, social and emotional development, and changing interests. The traditional criteria for evaluating children's literature are by seeing the elements such as plot, setting, theme, characterization, style, and format. Specialized criteria need to be applied to different types of literatur, such as picture books, biographies, and informational books. Additional criteria are also needed, for example, criteria for realistic story would not be the same as those used for modern fantasy. Historical fiction requires the added criteria of authenticity of setting and mood.

Of prime importance in any work of fiction, a child's first interest might lie on the plot. The plot in children's literature would better be presented in linear fashion, usually children do not have the maturity to follow several plots of many flash backs in time or place. The climax of a story should be easily identifiable and develop naturally from the story. Children prefer a swift conclusion following the climax, but the denouement should unite the loose ends of the story. Plots is but one element of good writing. If a book does not have a substantial plot, it will not hold children's interest long. Well-loved books, however, contain indefinable qualities and are memorable for more than plot alone.

The second element, setting is important in creating mood, authenticity, and credibility. The accident of place and time in a person's life may be as 
significant as the accident of birth. For the places life sets readers down can be tremendously important in person's life and story.

The point for the evaluation of any story is its overarching theme. The theme provides a dimension to the story that goes beyond the action of the plot. The theme of a book might be the acceptance of self or other, growing up, the overcoming of fear or prejudice. The theme of a story should be worth imparting to young people and be based upon justice and integrity, while sound moral and ethical principles should prevail. One thing to take care is the fact that the theme of children's books override the plot. Authors may be so intent on conveying a message that story or characterization may be neglected.

True characterization is another half mark of fine writting. The people potrayed in children's books should be as convicingly real and live like as their next-door neighbors. Besides, there should be consistency should not conform to a pattern but to the true nature of the characters as the author has presented him. Characters should speak and act in accordane with their age, culturer and educational background. Another aspect of sound characterization is growth and development. Not all characters will change, of course, but many are memorable for their personality development.

Style is also an important aspect for evaluating the children's literature. Children do not enjoy a story that is too descriptive, but they can appreciate figurative language, provided that the comparisons are within their background of understanding. The tastes of children place some demands on the writer's style. Children tend to want action in their stories and prefer a style that has movement rather than too much description or introspection. Children also demand 
conversation in their stories. They dislike a story that is too sentimental, and they see through the disguise of the too moralistic tales of the past.

Format of a bok including the size, shape, design of pages, illustrations, typography, quality of paper, and binding will be an important factor in a child's decision to read a story. While illustrations are not essential in books for older children, they may enrich the interpretation of the story, and should be carefully planned and integrated with the text, there are other factors that need to be considered in the format of a book such as the typography, the type should be large enough for easy reading by the age level for which it was intended. At the same time, if the type face is too large, children will consider the book "babysh". The space between the lines should be sufficient enough to make the text clear.

\section{UNDERSTANDING CHILDREN AND LITERATURE}

Fostering enjoyment and appreciation for literariness comes from knowing the age and phsycological disposition of children, those dispositions that cause a child to like a particular book. Child development has contributed knowledge about children that provides certain guideposts for selecting books. Exciting new developments have occured in the research in children's cognitive and language growth which have direct application for the choice of appropriate books for boys and girls.

Jacobson (1960) tried to answer the question of literalness by distinguishing six functions of language: the emotive, phatic, referential, metalingual, conative and poetic function. In verbal art, the poetic function is dominant. As Waugh (1980) points out, the referential function is the most clearly 
delimited opposite of the poetic function. Focus on the message itself entails the emphasizing the referential aspects ot that message.

From a contemporary point of view, one is likely to infer that the "set toward the message" should be understood in terms of a reader's attitude. Van Dick and Kintsch (1983) distinguish between two general types of language understanding strategies: contextual and textual strategies. Contextual strategies are general because they are not uniquely tied to natural language understanding, they can be categorized as cultural, social, and interaction strategies. Pragmatic strategies are on the borderline between contextual and textual strategies and enable readers to link textual structure with context, especially the interact ional strategies. They combine two shorts information: properties of utterance and properties of pragmatic context. While readers make use of some set of strategies for all types of the discourse, different patterns of behavior may emerge depending on the emphasis readers place on the particular strategies. For example, it may be assumed that literary readers place more emphasis on stylistic and rhetorical strategies than do news readers. This emphasis should produce different patterns of reading behavior; for instance, literary readers will recall more of the exact wording of a text than newsreaders.

Concerning the children's literature, one needs to be aware ot the dimensions of growth of each child. In the early decades of child study emphasis was placed upon discovery of "normal" behavior patterns for each age. Growth studies revealed similarities in pattern of physical, mental, and emotional growth. More recently, longitudinal studies have shown wide variables in individual raters of growht. Within one child growth may be uneven and spurt in one aspect of 
development may precede a spurt in another. Age trend continues to be importain in understanding the cild, but recent research has been concerned with the interaction of biological, cultural and life experiences foces. Experiences affect of the age at which development may appear. The cild-development point a view begins which the recognition and the acceeptance of the uniqueness of childhood. Childern are not miniature adult but individuals whith their own rights,needs,interest, and capacties. This concept suggests a need for literature the captures the wonder,humor,and disappointment of childhood.

There are some aspect to note concerning the cild's status of being. First, the physical development that not only influences their attention span but also their interests. The children's level of development, their rate of development and their varying interests may help determine what kinds of books are appropriate for them.

Second, Inhelder and piaget (1962) proposed that intelligence develops as a result of the learning of interaction of environment and the maturation of the child. All children indeed go throught stages of intellectual development in the same progression; but no necessarily of the same age. The sensory-characteristic of the learning of infants to toddlers of about two years. The child learns during this priod throught coordinating sensory perception and motor activity. The child in the preoperational period learns to represent his world symbolically through the medium of language, play and drawing. Characteristic of the cognitive growth of the child during the preopertational stage is the tremendous increase in language development and concept formation. As children move from the preoperational to the concreteoperational level of thought that is flexibel and reversible, children in 
this period can accept stories within stories as represented by Yashima's seashore story. The last point of cognitive development is described by Piaget as the period of the normal operations and appears in early adolescence at the age of eleven or twelve years and on. The youngster is now capable of abstract theoterical thought, reasoning from hypothesis to logical conclusions. He can hold several plot or subplots in his mind and sees the interrelationship among them.

Third, characteristic of the development of all children is the phenomenal growth language which occurs during the preschool years. While there are different points concerning how children acquire language, most of language theorists would consider the importance of providing a rich language environment of the young child. Cazden (1972) sees that the child's oral language develops when richly supplied cafetaria of language is available of beginning. While it is not the purpose of this paper to give detail-description of language acquisition it is necessary to discuss the role of literature plays in developing the language power of children.

One study by Irwin (1960) indicates that the systematic reading of stories to infants over an eighteen-month period will increase the spontaneous vocalization of two and half year-old children. Meanwhile, Cohen's study (1968) showed the positive effect that reading aloud had on twenty classes of seven years-old in Harlem, New York City. In this study the ten characters in the experimental classes read for twenty minutes daily from a carefully selected list of children's books. Following the reading of the story, the children were asked to do something with the book make it a memorable experience to them. This involves discussing it, dramatizing it, or interpreting through art or music. At the end of the 
years, the experimental classes had gained significantly in their vocabulary and reading comprehension scores. Chomsky (1972) measured the language acquisition of thirty-six children between the ages of six and ten and found the high possitive correlation between their linguistic stage of development and their previous experience of literature.

This study confirms the findings of the others; evidently reading the children increases their language development, while those children who have the high linguistic competence are the ones who have been exposed to much literature. On the basis of these researches alone, all teachers and librarians should feel responsible to read aloud to the children in their school everyday, for literature offers the child creative and qualitative opportunitiea to extend and enrich their language development.

\section{FACILITATING LEARNING AT INDONESIAN SCHOOLS}

It is well known that every aspect of growth is intertwined with every other. All learning is a meshing of cognitive dimensions, effective or emotional responses, social relationship and value orientation. The processs of "becoming" is highly complex one indeed to becoming a fully-functioning person, the child's basic need must be met. Behavior is consistent with the child's perception of environment at the moment and with his continuing purpose of enhancing the self. Marslow (1970) suggests that a person develops through a hierarchy of needs from basic animal-survival necessities to the higher more uniquely human and spiritual needs. While some higher level animals such as the apes appear to have needs of belongings and even esteem only human seek to reach their greatest 
potential in the self actualizing process in which they are at last free to be themselves. The following is Moslow's hierarchy of needs.

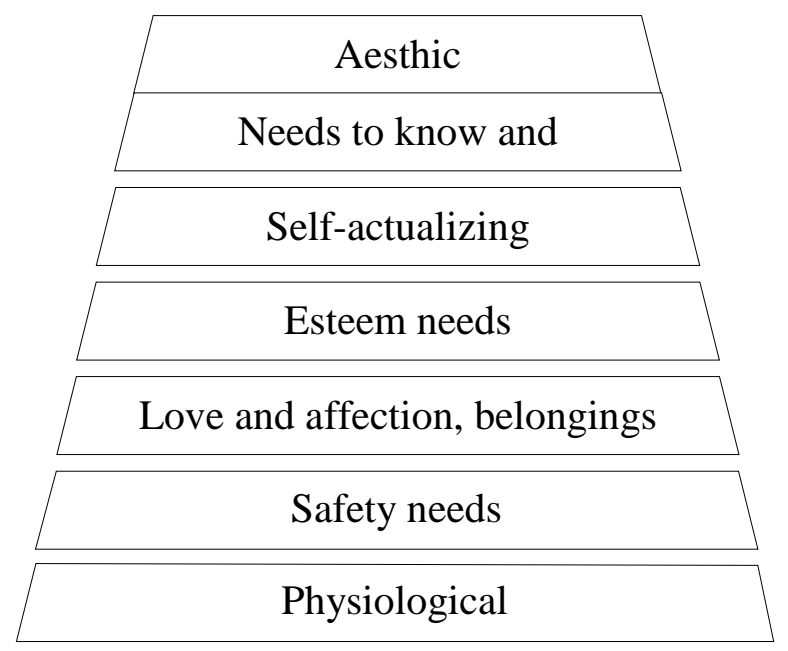

Figure 1. Marslow's hierarchy needs

Books alone cannot bring about the satisfaction of basic needs. Literature may provide opportunities for identification and for understanding the self and others. Books may contribute to feeling of success as children satisfy their desires for new experiences, gain new insights into their behavior and that for others.

Investigations of the learning process have yielded the general agreements on conditions that facilities learning. The following guides any be useful in planning the literature programin the elementary school:

1. The child is an active participant in his own learning.

2. Children learns best through first-hand experiencing, active contact with a stimulating environment.

3. The learner reacts as a whole. Anxiety and interest are involved in learning.

4. A single experience may result in multiple learning, including development of values and attitudes. 
5. Learning and behavior result as the behaver perceives the situation. The development, including level of aspiration, influences learning.

6. Readiness for learning involves finding the right match for the child's development level.

7. Readiness is influenced by the child's perception of the values and meanig of the task, as well as the interplay of biological and environmental factor. Instruction can faster readiness.

8. Rewards include the satisfactions of neew experiences and feelings of accomplishment.

9. Learning through intrinsic motivation is preferable to learning through intrinsic motivations.

10. Learning is facilitated as the learner is clued into the structure of the content and the learning process itself.

11. Participation in selecting and planning the learning activity increases interest.

12. Each learner is unique in his perception. He interprets experience according to his own 'sets'.

13. Achievement is an interaction between the inner growth potential of the child and the child and the experience, learning or nature he has been given.

When all things above have been considered, it can be expected that literature can both develop an extend children's interests. Teachers and librarians need to know what are the current interests of the children they serve, so that they might better provide the books to meet these immediate needs. It is also useful to know what children of particular age level generally like, recognizing, howeverm 
the danger of stereotyping children's interests without regards to their backgrounds, reading abilities, or personal needs/

Children's reading interests reflect the pattern of their general interests. Stories of animal, realistic fiction, adventure and exploration, biographies, and strories of the past- all have appeal for them humor make believe, suspense, and action are the qualities that children enjoy most in their reading. It has been known from studies that there are many factors influencing the children's reading interests such as age, format of book, environment that must be given attention. Adults who are responsible for children's reading need to be aware of the guides from child development, learning theory, and children's interest. They must also recognize characteristics and needs of children at different ages and stages of development. At the same time, it is important to remember that each child has unique pattern of growth.

However, in the case of Indonesia children, there are a few points to consider in designing the literature program for them. First, the cognitive and psychological state of Indonesia children might be different from those in Europe or United States. This may be influenced by the social, economic, and cultural background of the children. Therefore, literary tastes, interest, and tendency of Indonesia children may differ from the western children. Indonesian children are probably more oriented towards simple ness of life in their surrounding. Second, those interested in designing literature for children must be aware of the limited number of book publication for children. Majority of published stories found in magazines or newspapers are often too simplified too regarding the complexity of child's perception on life. Thus it often does not properly stimulate better learning 
for the children. Third, it must be understood that all efforts of designing literature for children may invite a little support from the public. This may be due to the lack of awareness of the importance of literature, the commercial consideration, and educational system. It is obvious then that the effort of designing literature for children is not an easy job, but a very time-cosuming one.

\section{REFERENCES}

Aberson, F.P. 1981 Psychological Status of the Script Concept. American Pyschologist 36: 715 - 729

Cazden, C.B. 1972. Child Language and Education. New York: Holt, Rinechart, and Winston.

Chomsky, C. 1972. Stages in Language Development and Reading Exposure. Harvard Educational Review 42: 1 - 33.

Gibbs, R.W, Krushner, J.M, and Mills, W.R. 1991. Authorial Intentions and Metaphor Comprehension. Journal of Psychologistic Research 20: 11 - 30.

Huck, C.S. 1976. Children Literature in Elementary School. New York: Holt, Rinehart, and Winston.

Inhelder, B and Piaget, J.I. 1962. The Growth of Logical Thinking. New York: Basic Book.

Irwin, O-C. 1960. Infant Speech: Effect of Systematic Reading of Stories. Journal of Speech and Hearing Research 3: 187 - 190.

Jacobson, R. 1960. Closing Statement: Linguistic and Poetic. in T.A. Sebeok (ed). Style in Language. Cambridge: The M.I.T Press.

Marslow, A.H. 1970. Motivation and Personality. New York: Helper and Row.

Strieder, J. 1989. Literary Structure, Evolution and Value: Russian Formalism and Chezh Structuralism Reconsidered. Cambridge: Harvard University Press.

Waugh, L.R. 1980. The Poetic Function and Nature of Language. Poetics 2: 57 82.

Zwaan, R. 1993. Aspects of Literary Comprehension. Amsterdam: John Benyamins Publishing Company. 